\title{
Vimentin and Notch as biomarkers for breast cancer progression
}

\author{
GLORIA M. CALAF ${ }^{1,2}$, ADAYABALAM S. BALAJEE ${ }^{2}$, MARIA T. MONTALVO-VILLAGRA ${ }^{3}$, \\ MARIANA LEON ${ }^{3}$, DANIELA NAVARRETE M. ${ }^{4}$, RAÚL GONZÁLEZ ALVAREZ ${ }^{4}$, \\ DEBASISH ROY ${ }^{5}$, GOPESHWAR NARAYAN ${ }^{6}$ and JORGE ABARCA-QUINONES ${ }^{7}$ \\ ${ }^{1}$ Institute for Advanced Research, Tarapacá University, Arica 8097877, Chile; ${ }^{2}$ Center for Radiological Research, \\ Columbia University Medical Center, New York, NY 10032, USA; ${ }^{3}$ Departament of Health Science, Faculty of Science, \\ Tarapacá University, Arica 8097877; ${ }^{4}$ Department of Pathology, Dr. Gustavo Fricke Hospital of Viña del Mar, \\ Valparaiso 2581907, Chile; ${ }^{5}$ Department of Natural Sciences, Hostos College of the City University of New York, Bronx, \\ NY 10451, USA; ${ }^{6}$ Department of Human Molecular Genetics, Banaras Hindu University, Varanasi 221005, India; \\ ${ }^{7}$ IREC, School of Medicine, IREC, St. Luc Hospital, University of Louvain, Brussels 1200, Belgium
}

Received April 28, 2013; Accepted November 6, 2013

DOI: $10.3892 / 01.2014 .1781$

\begin{abstract}
Breast cancer, the most common spontaneous malignancy diagnosed in women, is a classical model of hormone dependency as it is associated with prolonged exposure to female hormones. Different cytoplasmic proteins are important in the transformation of a normal cell to an invasive tumor cell, and these include vimentin and Notch. To investigate the importance of these two genes and proteins in breast carcinogenesis, we used an in vitro breast cancer model system, in which an immortalized human breast epithelial cell line, MCF-10F, was malignantly transformed by exposure to low doses of high linear energy transfer $\alpha$ particle $(150 \mathrm{keV} / \mu \mathrm{m})$ radiation and subsequent growth in the presence or absence of $17 \beta$-estradiol. This model consisted of human breast epithelial cells in different stages of transformation: i) a parental cell line (MCF-10F), ii) an Estrogen cell line (MCF-10F continuously grown with estradiol at $10^{-8}$ ), iii) a malignant and non-tumorigenic cell line (Alpha3), iv) a malignant and tumorigenic cell line (Alpha5) and v) a Tumor 2 cell line derived from a xenograft of the Alpha5 cell line injected into nude mice. Vimentin and Notch showed greater expression in the Alpha5 and Tumor2 cell lines compared with that in the non-tumorigenic cell lines, MCF-10F, Estrogen and Alpha3. In the present study, positive staining for vimentin was found in $21 \%$ of cases. Vimentin and Notch protein expression was negative in noninvasive ductal carcinoma biopsies from breast cancer patients. However, positive cell expression was observed in invasive ductal carcinoma biopsies. These biomarkers can be considered important
\end{abstract}

Correspondence to: Dr Gloria M. Calaf, Institute for Advanced Research, Tarapacá University, Calle Antofagasta 1520, Arica 8097877, Chile

E-mail: gmc24@columbia.edu

Key words: biomarkers, estrogen, radiation, breast cells, vimentin, Notch indicators of breast cancer progression and can be added to the diagnostic panel when overall survival is a primary end-point.

\section{Introduction}

Breast cancer, the most common spontaneous malignancy diagnosed in women, is a classical model of hormone dependency. There is evidence that breast cancer risk is associated with prolonged exposure to female hormones, as the onset of menarche, late menopause and hormone replacement therapy are associated with greater cancer incidence (1). The progression of breast cancer follows a complex multi-step process that depends on various exogenous (diet and breast irradiation) and endogenous (age, hormonal imbalances, proliferative lesions and family history of breast cancer) factors (2-4). Breast cancer is a complex disease in which numerous genetic aberrations occur. Cellular and molecular changes that occur during the development of cancer can be mediated by a range of endogenous and environmental stimuli. On the basis of the currently accepted view of breast cancer as a multi-step process, it is possible that specific abnormalities may be an essential part of the transformation of a normal cell to an invasive tumor cell.

Different cytoplasmic proteins are key in the transformation of a normal cell to an invasive tumor cell and among these, vimentin is particularly important. It is one of the cytoplasmic intermediate filament proteins, which are the major components of the cytoskeleton normally found in embryonic or mesenchymal stem cells $(5,6)$. However, vimentin is frequently expressed in neoplastic cells with metastatic properties, including breast cancer cells $(7,8)$. It is a 57-kDa intermediate filament protein, which forms a part of the cytoskeleton. Expression of vimentin and cytokeratins has also been described in breast carcinomas. Hendrix et al (9) demonstrated that the co-expression of vimentin and keratin intermediate filaments in human breast cancer cells results in phenotypic inter-conversion and increased invasive behavior.

Another important gene, Notch, is also pivotal in this context. This gene is expressed in a variety of tissues, indicating that it is involved in multiple signaling pathways (10-14). 
It is either overexpressed or rearranged in human tumors, such as is the case with the 280 - to $330-\mathrm{kDa}$ Notch protein (14). The LIN-12/Notch family of transmembrane receptors is believed to be central to development by regulating cell fate decisions (10-13). Notch signals are involved in the development and maintenance of normal tissues that are recapitulated in different forms of cancer $(14,15)$. Notch can either promote or limit tumor growth, depending on the tumor type, through differentiation, cellular metabolism, cell cycle progression, angiogenesis and possibly self-renewal and immune function $(16,17,19,20)$. The Notch signaling pathway is critical in cell fate decisions, tissue patterning and morphogenesis, and is hence regarded as a developmental pathway. However, problems with this pathway can contribute to cellular transformation and tumorigenesis.

The expression of Notch receptors and their downstream target genes is upregulated in primary human melanomas $(15,16)$, and the expression of constitutively active Notch1 promotes melanoma progression $(15,17)$. These oncogenic effects correlate with the activation of Wnt signaling in melanoma cells (15), which promotes the expression of adhesion molecules such as $\mathrm{N}$-cadherin (17) through the transcription factor TCF/LEF (15). Notch has also been implicated in the pathogenesis of other solid tumors, such as medulloblastoma $(18,19)$ and ovarian cancer $(20)$, and the number of known neoplasms involving some alteration in Notch signaling is increasing. The aim of the present study was to assess whether vimentin and Notch gene and protein expression are altered in breast cancer progression. The importance of vimentin expression was analyzed by identifying cases of breast cancer with poor prognosis and comparing vimentin and Notch as biomarkers required for prognosis in breast cancer patients.

\section{Materials and methods}

Cell lines. MCF-10F cells were grown in DMEM/F-12 (1:1) medium supplemented with antibiotics $[100 \mathrm{U} / \mathrm{mI}$ penicillin, $100 \mu \mathrm{g} / \mathrm{ml}$ streptomycin and $2.5 \mu \mathrm{g} / \mathrm{ml}$ amphotericin B (all from Life Technologies, Grand Island, NY, USA)] and $10 \mu \mathrm{g} / \mathrm{m}$ of $5 \%$ equine serum (Biofluids, Rockville, MD, USA), $0.5 \mu \mathrm{g} / \mathrm{ml}$ hydrocortisone (Sigma-Aldrich, St. Louis, MO, USA) and $0.02 \mu \mathrm{g} / \mathrm{ml}$ epidermal growth factor (Collaborative Research, Bedford, MA, USA) (21). An in vitro experimental breast cancer model (Alpha model) (22), developed by exposing the immortalized human breast epithelial MCF-10F cell line to low doses of high linear energy transfer $\alpha$ particle radiation $(150 \mathrm{keV} / \mu \mathrm{m})$ and subsequent growth in the presence or absence of $17 \beta$-estradiol, was used in this study. This model consisted of human breast epithelial cells in different stages of transformation: i) a control cell line (MCF-10F), ii) an Estrogen cell line [(MCF-10F continually treated with estradiol at $10^{-8} \mathrm{M}$ (Sigma-Aldrich)], iii) a malignant but non-tumorigenic cell line (Alpha3), iv) a malignant and tumorigenic cell line (Alpha5) and v) a Tumor 2 cell line derived from cells originating from a tumor after injection of the Alpha5 cell line into nude mice. A total of 21 female CB17 SCID mice (Taconic, Germatown, NY, USA) and nude mice (Harlam Sprague Dawley, Indianapolis, IN, USA) (age, 1 year) were used in these studies. Each animal was injected subcutaneously at two different sites with $8 \times 10^{6}$ cells in $0.2 \mathrm{ml}$ saline in the fat pad of the right and left side of the abdominal mammary gland. The study was approved by the ethics committee of Columbia University Medical Center (New York, NY, USA)

Pathological analysis. Formalin-fixed, paraffin-embedded, noninvasive and invasive ductal and lobular carcinomas were obtained from the archives of the Pathology Department of Dr Gustavo Fricke Hospital, Viña del Mar, Valparaíso, Chile. Patients had undergone surgery (total mastectomy with axillary lymph node dissection) between 1997 and 2001. The median patient age at surgery was 56 years (range, 25-92 years). The primary pathological diagnosis was confirmed by hematoxylin and eosin staining. All operative and pathological reports were reviewed to confirm disease stage. Sections of $2 \mu \mathrm{m}$ were cut and mounted onto polylysine-coated slides, and stained for vimentin and Notch protein expression. The study was approved by the ethics committee of Dr. Gustavo Fricke Hospital of Viña del Mar (Valparaiso, Chile).

Immunoperoxidase staining. Protein expression was evaluated as previously described (22-24). Exponentially growing cell lines were plated on a glass chamber slide (Nunc Inc., Naperville, IL, USA) at a density of $1 \times 10^{4}$ cells/ml of medium and allowed to grow for 2-3 days until they reached $70 \%$ confluence (21). The cells were fixed with buffered paraformaldehyde at room temperature, incubated with $1 \% \mathrm{H}_{2} \mathrm{O}_{2}$ in methanol to block endogenous peroxidase and washed twice with buffer solution. Cell cultures were subsequently covered with normal horse serum for $30 \mathrm{~min}$ at RT and incubated with anti-rabbit monoclonal antibody (vimentin: C-20, sc 7557 and Notch 4: C-19, sc 8644) (Santa Cruz Biotechnology, Inc., Santa Cruz, CA, USA) at a 1:500 dilution at $4^{\circ} \mathrm{C}$ overnight, and then incubated for $45 \mathrm{~min}$ with diluted biotinylated secondary antibody solution (Vector Laboratories, Burlingame, CA, USA) and Vectastin Elite ABC Reagent (Vector Laboratories). The experiments were repeated three times in cells with identical passages in vitro. The number of immune-reactive cells (50 cells/field) was counted in several randomly selected microscopy fields (x400) per sample using an optical microscope (CX31; Olympus Corporation, Tokyo, Japan). Ten fields were counted for each cell line.

Inmunofluorescent staining. Protein expression was evaluated by immunofluorescent staining and confocal microscopy as previously described $(22,23)$. Cells were viewed on Zeis Axiovert 100 TV microscope (Carl Zeiss, Thornwood, NY, USA) using a 40X 11.3 NA objective lens equipped with a laser scanning confocal attachment (LSM 410, Carl Zeiss). A semi-quantitative estimation of the area and the intensity of the staining of the cells present in the culture dishes were performed based on the relative staining of the protein expressed by the controls and transformed cells.

Fluorescent-labeled probe preparation for microarray analysis. The poly(A) mRNA from normal, radiation- and estrogen-treated breast cell lines was isolated using a QIA-direct-mRNA isolation kit (Qiagen, Inc., Valencia, CA, USA). Fluorescent-labeled cDNA was prepared from $1 \mu \mathrm{g}$ of each of these poly(A) mRNA samples by 
A
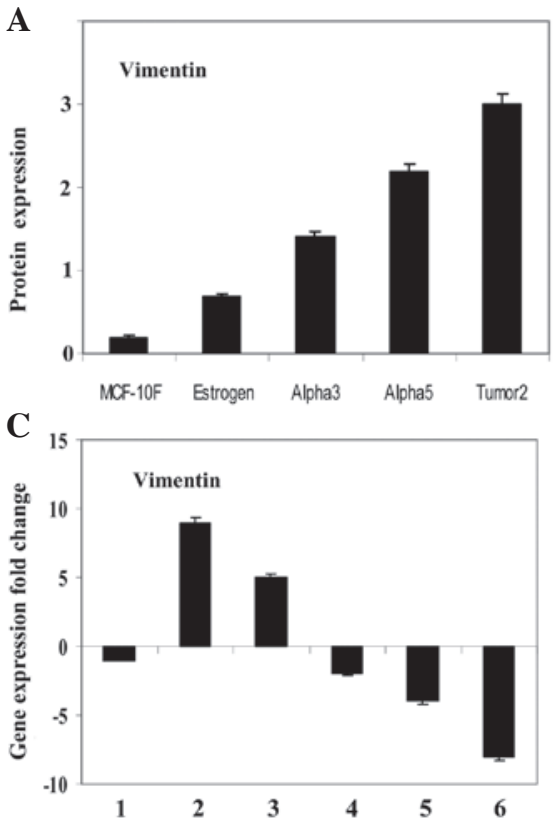
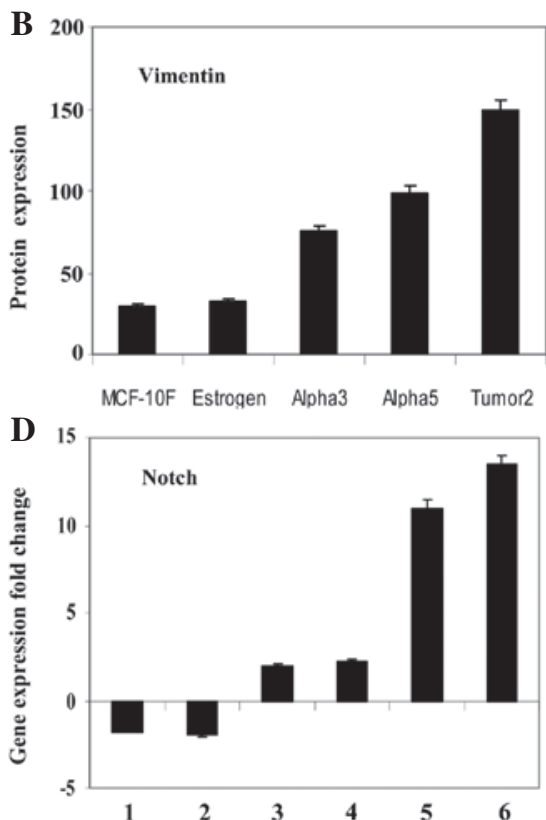

Figure 1. Bars represent the average and standard error of vimentin protein expression by (A) peroxidase and (B) immunofluorescent techniques of the MCF-10F, Estrogen, Alpha3, Alpha5 and Tumor 2 cell lines. The primary antibodies used were mouse monoclonal antibodies (Santa Cruz Biotechnology, Inc., Santa Cruz, CA, USA). Fold change of (C) vimentin and (D) Notch gene expression. Gene expression from scatter plots of the following pairwise comparative studies of cell lines: MCF-10F/E (1), MCF-10F/Alpha3 (2), E/Alpha5 (3), Alpha3/Alpha5 (4), Alpha 3/Tumor2 (5) and Alpha5/Tumor2 (6).

using oligo dT-primed polymerization and a Superscript II reverse transcriptase kit (Life Technologies) in the presence of either Cy3- or Cy5-labeled dCTP, following the usual procedure (http://cmgm.stanford.edu/pbrown/protocols/). The appropriate $\mathrm{Cy} 3$ - and $\mathrm{Cy} 5$-labeled probes were pooled and hybridized to microarray glass coverslips for $16 \mathrm{~h}$ at $65^{\circ} \mathrm{C}$ and then washed with high stringency for analysis.

Affymetrix HG-U133A Plus 2.0 GeneChip microarray gene expression analysis. The breast cancer model (Alpha model) containing i) MCF-10F, ii) Estrogen, (iii) Alpha3, iv) Alpha5 and v) Tumor2 cell lines was analyzed for gene expression using Affymetrix U133A oligonucleotide microarray (Affymetrix, Santa Clara, CA, USA), which contains 14,500 genes. Arrays were quantitatively analyzed for gene expression using the Affymetrix GeneChip Operating Software, with dual global scaling option in a Genes@Work software platform of discovery algorithm, Structural Pattern Localization Analysis by Sequential Histograms, and a false discovery rate of $0.05(25,26)$.

\section{Results}

Phenotypic and molecular analysis of vimentin expression in breast cancer progression model. The established breast cancer model (22) has been shown to exhibit important phenotypic characteristics of breast carcinogenesis. The normal cell line, MCF-10F, did not exhibit any of the features that characterize malignant cells, such as anchorage-independent growth in soft agar, invasion and tumor growth in nude mice $(22,24)$. The Alpha3 cell line formed colonies in soft agar and had invasive capabilities, but failed to form tumors in the immuno-suppressed mice. However, the Alpha5 cell line induced mammary gland tumors in the animals and metastasis in the liver, lung and kidneys after injection. This cell line gave rise to the Tumor 2 cell line after removal of the mammary tumor, digestion in in vitro conditions and culture for many passages.

The analysis of immunoperoxidase (Fig. 1A) and immunofluorescence (Fig. 1B) data obtained in relation to the relative vimentin expression in MCF-10F, Estrogen, Alpha3, Alpha5 and Tumor 2 cell lines indicated that such expression was significantly greater $(\mathrm{P}<0.05)$ in the Tumor2, Alpha3 and Alpha5 cell lines, when compared with the MCF-10F and Estrogen cell lines. Genes that were identified to be differentially expressed between cell lines of this model were also studied. Histogram plots of the differential expression of vimentin and Notch genes in these cell lines were detected by gene chip array. Results of pairwise comparisons of cell lines examined for vimentin protein expression were analyzed with the following pairs of cell lines: MCF-10F/Estrogen, MCF-10F/Alpha3, Estrogen/Alpha5, Alpha3/Alpha5, Alpha5/Tumor2 and Alpha 3/Tumor2 (Fig. 1C). Results of the pairwise comparisons did not reveal any alteration in vimentin gene expression between the MCF-10F and Estrogen cell lines, while there was an almost nine- and five-fold alteration in the MCF-10F/Alpha3 and Estrogen/Alpha5 combinations, respectively. There were six- and four- fold changes in gene expression between the Alpha5 and Tumor 2 cell lines, and Alpha3 and Tumor 2 cell lines, respectively.

Results of pairwise comparisons of cell lines examined for Notch gene expression are shown in Fig. 1D. Results of the same pairs of cell lines were analyzed, revealing no alteration in Notch gene expression between the MCF-10F and Estrogen cell lines, Estrogen and Alpha5 cell lines, and Alpha3 and Alpha5 cell lines. By contrast, there was an almost ten- and fourteen-fold alteration in the Alpha5/Tumor2 and Alpha3/Tumor 2 combinations, respectively, with higher expression in Alpha3 and Alpha5 than in Tumor2. 

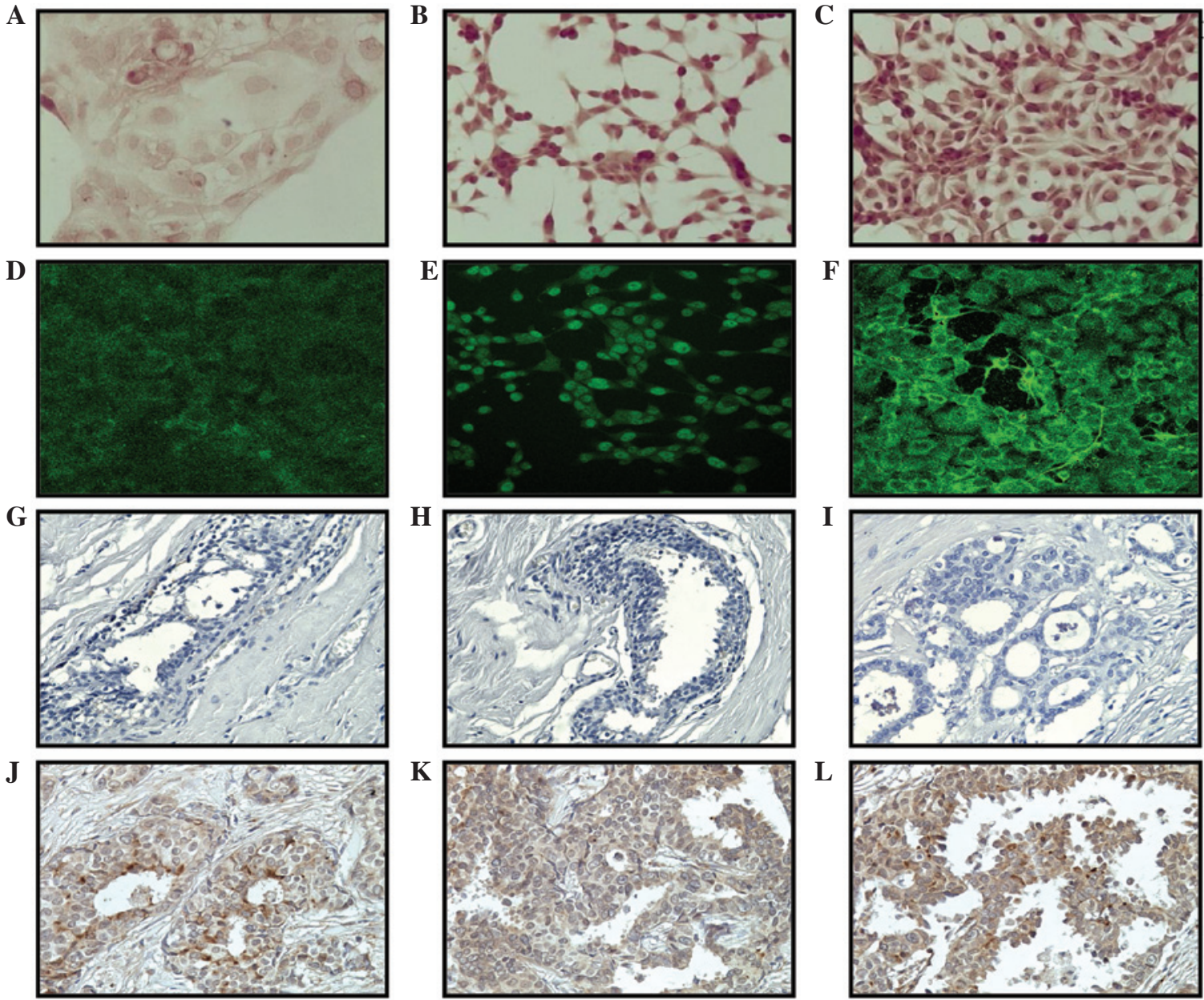

Figure 2. Representative images of vimentin protein expression stained by (A-C) immunoperoxidase and (D-F) immunofluorescent techniques in a breast cancer cell model. Biopsy specimens containing (G-I) ducts and lobules, and (J-L) invasive carcinoma determined by inmunoperoxidase techniques (magnification, x400).

A
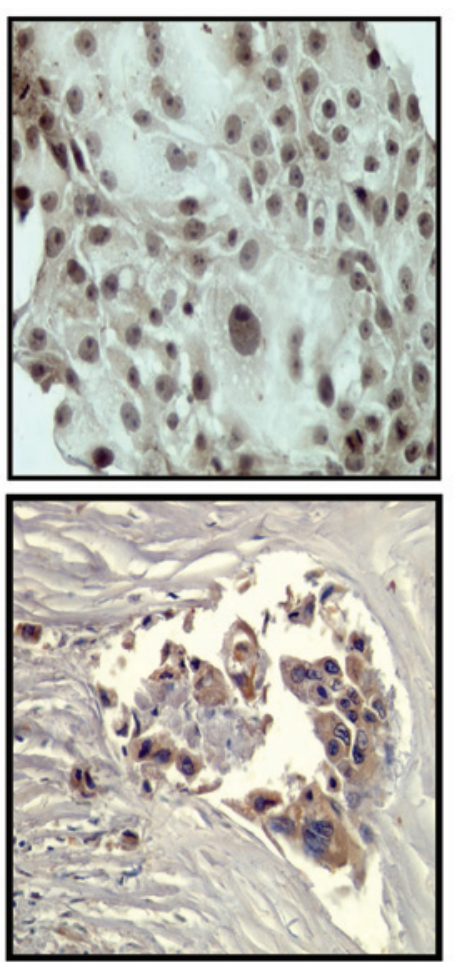

B

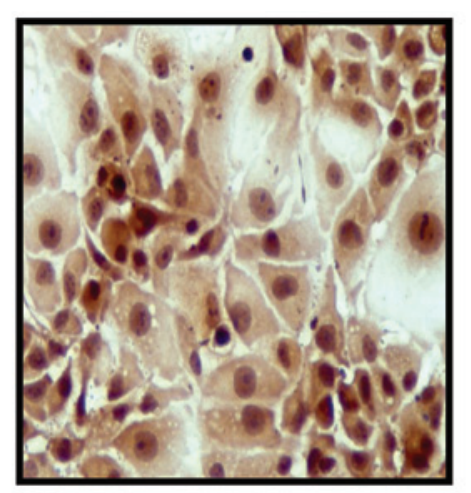

E

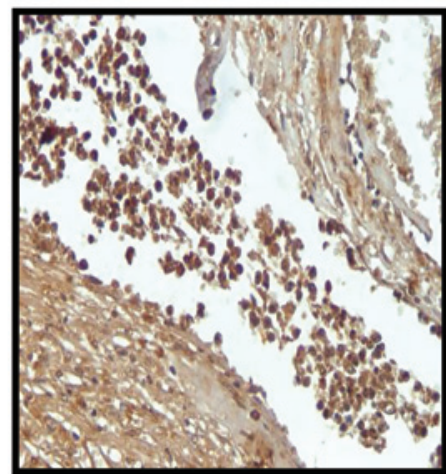

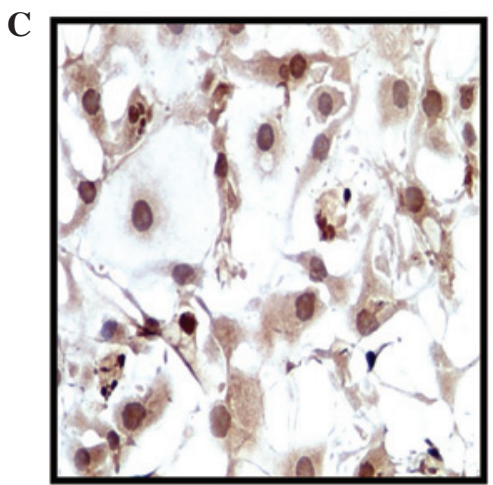

$\mathbf{F}$

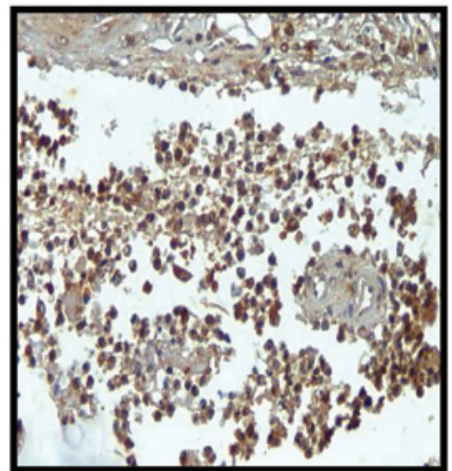

Figure 3. Notch protein expression of (A) MCF-10F; (B) Alpha5; (C) Tumor2 cell lines. Biopsy specimens containing (D) ductal carcinoma and (E and $\mathrm{F}$ ) invasive ductal carcinoma determined by immunoperoxidase technique (magnification, $\mathrm{x} 400$ ). 
Vimentin protein expression in breast cancer model and breast biopsy specimens. Representative images of vimentin protein expression, in which greater expression was observed in the Alpha5 and Tumor 2 cell lines compared with that in the control MCF-10F cell line, can be observed in immunoperoxidase (Fig. 2A-C) and immunofluorescence (Fig. 2D-F) studies. Biopsy specimens were also analyzed for vimentin protein expression to analyze progression in breast cancer. Fig. 2G-I shows representative tissues of vimentin protein expression in ducts found in sections of biopsies from breast cancer patients, as determined by immunoperoxidase staining. This expression was negative in noninvasive ductal carcinoma and breast epithelial lesions surrounding the primary tumors, ductal and lobular hyperplasia, and microcytes. By contrast, this expression was positive in breast specimens with invasive characteristics, as shown in Fig. 2J-L. Positive staining for vimentin was found in $21 \%$ of cases.

Notch protein expression in breast cancer model and breast biopsy specimens. In the present study, non-malignant and malignant cell lines from the model were used to analyze Notch protein expression. Fig. 3A-C shows higher Notch protein expression in the Alpha5 and Tumor 2 cell lines compared with that in the control MCF-10F cell line, as determined by immunoperoxidase staining. Samples from biopsy specimens showed negative Notch protein expression in noninvasive ductal carcinomas. However, positive cell expression was observed in those tissues with cells from invasive ductal carcinomas (Fig. 3D-F), particularly in invasive isolated tumor cells. Positive staining for Notch was found in $25 \%$ of cases.

\section{Discussion}

The main purpose of the present study was to assess the prognostic value of the markers vimentin and Notch. Identification of factors involved in cell proliferation and transformation has been facilitated by studies using various human epithelial cell lines. The analysis of immunoperoxidase and immunofluorescence data obtained in relation to the relative vimentin expression indicated that such expression was significantly greater in Tumor2 and Alpha5 when compared with MCF-10F, Estrogen and Alpha3 cell lines.

Results of pairwise comparisons of vimentin gene expression in the different cell lines indicated that there was no alteration in vimentin gene expression between the MCF-10F and Estrogen cell lines, while there was an almost nine- and five-fold alteration in the MCF-10F/Alpha3 and Estrogen/Alpha5 combinations, respectively. There were six- and four-fold changes in gene expression between Alpha5 and Tumor2, and Alpha3 and Tumor2, respectively. Results of the same pairs of cell lines analyzed for Notch gene expression indicated that there was no alteration between the MCF-10F and Estrogen, Estrogen and Alpha5, and Alpha3 and Alpha5 cell lines. By contrast, there was an almost ten- and fourteen- fold alteration in the Alpha5/Tumor2 and Alpha3/Tumor2 combinations, respectively, with higher expression in Alpha3 and Alpha5 than in Tumor2 cells. Vimentin protein expression in ducts in sections of biopsies from breast cancer patients was found to be negative for noninvasive ductal carcinoma, but positive for ductal carci- noma with invasive characteristics. Vimentin-reactive cells in benign and malignant breast tissue have been described in many studies (26-29). These studies reported that vimentin expression appeared to be associated with poor prognosis in node-negative ductal breast carcinomas, and that vimentin was preferentially expressed in human breast carcinomas with low levels of estrogen receptors. Gene expression patterns of breast carcinomas distinguished tumor subclasses with clinical implications (30). A possible association was found between the clinically aggressive behavior of tumors $(28,29)$ and estrogen receptor negativity (31,32), high Ki-67 levels (32) and poor differentiation of tumors with high-grade and positive vimentin protein expression. Domagala et al (29) reported that vimentin was preferentially expressed in high-grade ductal and medullary, but not in lobular, breast carcinomas. Other data showed that more invasive breast cancer lines expressed vimentin, indicating its usefulness in identifying cases with poorer prognosis $(28,29)$.

Vimentin is known to be selectively expressed in aggressive breast cancer cell lines (9). Elevated vimentin expression levels correlate well with upregulated migration and invasion of cancer cells $(9,26)$. Sommers et al (27) showed that transfection of noninvasive human breast cancer cell lines, such as MCF7, with the vimentin gene led to accelerated invasiveness. The authors also reported vimentin rather than keratin expression in certain hormone-independent breast cancer cell lines, and in oncogene-transformed mammary epithelial cells. The possible association of vimentin with the clinically aggressive behavior of tumors described by others $(7,28-32)$ may be explained by the correlation of vimentin expression with a lack of steroid receptors and poor differentiation of cancer. Gilles et al (31) also found vimentin expression in cervical carcinomas was associated with invasive and migratory potential.

Thus, we can suggest an improved indicator of breast cancer progression by adding vimentin to the diagnostic panel when overall survival is a primary end-point. In the present study, positive staining for vimentin was found in $21 \%$ of cases, which is in line with previous findings (32). Therefore, vimentin expression appears to predict survival in ductal breast carcinoma.

Notch protein expression was also higher in the Alpha5 and Tumor 2 cell lines in comparison with that in the control MCF-10F cell line. When samples from biopsy specimens were analyzed for Notch protein expression, negative cells were found in noninvasive ductal carcinomas while positive cells were found in invasive ductal carcinomas. It has been reported that the Notch pathway is required for the establishment of embryonic hematopoietic stem cells (33), and it has been implicated in the maintenance of several types of normal cell populations (34-36). The effects of Notch on cells include increased survival or death, proliferation or growth arrest and commitment to, or blockage of, differentiation. These different outcomes are mediated through a novel signaling pathway in which Notch receptors on the cell surface give rise to a nuclear transcriptional activation complex. Studies on Notch are related to the understanding of how this pathway yields several outcomes. It has been proposed that Notch may serve as an oncogene or tumor suppressor, a repressor or inducer of terminal differentiation, or a cancer stem cell factor. Studies on the multifaceted role of Notch in cancer indicate a possible therapeutic implication. Notch signaling is 
frequently deregulated in breast cancer, and hyperactivation of Notch contributes to the tumor process. Notch has been shown to be involved in the controlled proliferation and migration of vascular endothelial cells, as well as in the integration of Notch and Wnt signaling, as observed in hematopoietic stem cell maintenance (34). Guentchev and McKay (35) observed that Notch controlled the proliferation and differentiation of stem cells in a dose-dependent manner. It has also been suggested that Notch acts as a transducer molecule for developmental processes. Stylianou et al (36) observed aberrant activation of Notch signaling in human breast cancer.

Estrogens are known to regulate the proliferation of breast cancer cells and to alter their phenotypic properties; the gene networks and pathways through which estrogenic hormones regulate these events have also been considered (37). We used global gene expression profiling by Affymetrix GeneChip microarray analysis to identify genes altered by the presence of estradiol in an MCF-10F human breast cancer model. Of the $>14,000$ genes analyzed, over 300 showed a pattern of either up- or downregulation. We observed a general upregulation of positive proliferation regulators, including multiple growth factors, genes involved in cell cycle progression and regulatory factor-receptor loops, and a downregulation of transcriptional repressors and anti-proliferative and pro-apoptotic genes, including BCL2 and TGF- $\beta$ family growth inhibitory factors. The present study highlights the diverse gene networks and metabolic and cell regulatory pathways through which this hormone operates to achieve its widespread effects on breast cancer cells.

It can be concluded that vimentin and Notch gene and protein expression are altered in breast cancer progression, thereby helping to identify cases of breast cancer with poor prognosis and complementing those biomarkers required for assessing the prognosis of breast cancer patients.

\section{Acknowledgements}

The support given by grants FONDECYT (GMC; no. 1120006) and MINEDUC-Universidad de Tarapacá (GMC) is greatly appreciated. The authors thank Guiliana Rojas Ordóñez and Georgina Vargas Marchant for their technical assistance, and Dr Manikandan Jayapal and Dr Prakash Hande of the National University of Singapore for the analysis of Affymetrix microarray data.

\section{References}

1. Henderson BE, Ross R and Bernstein L: Estrogens as a cause of human cancer: the Richard and Hinda Rosenthal Foundation award lecture. Cancer Res 48: 246-253, 1988.

2. Feigelson HS, Ross RK, Yu MC, Coetzee GA, Reichardt JK and Henderson BE: Genetic susceptibility to cancer from exogenous and endogenous exposures. J Cell Biochem Suppl 25: 15-22, 1996.

3. Krieger N: Exposure, susceptibility, and breast cancer risk: a hypothesis regarding exogenous carcinogens, breast tissue development, and social gradients, including blacklwhite differences, in breast cancer incidence. Breast Cancer Res Treat 13: 205-223, 1989.

4. Dickson RB and Lippman ME: Estrogenic regulation of growth and polypeptide growth factor secretion in human breast carcinoma. Endocr Rev 8: 29-43, 1987.

5. Duprey P and Paulin D: What can be learned from intermediate filament gene regulation in the mouse embryo. Intl J Dev Biol 39: 443-457, 1995.

6. Stewart M: Intermediate filament structure and assembly. Curr Opin Cell Biol 5: 3-11, 1993.
7. Gilles C, Polette M, Zahm JM, Tournier JM, Volders L, Foidart JM and Birembaut P: Vimentin contributes to human mammary epithelial cell migration. J Cell Sci 112: 4615-4625, 1999.

8. Whipple RA, Balzer EM, Cho EH, Matrone MA, Yoon JR and Martin SS: Vimentin filaments support extension of tubulin-based microtentacles in detached breast tumor cells. Cancer Res 68: 5678-5688, 2008.

9. Hendrix MJ, Seftor EA, Seftor RE and Trevor KT: Experimental co-expression of vimentin and keratin intermediate filaments in human breast cancer cells results in phenotypic interconversion and increased invasive behavior. Am J Pathol 150: 483-495, 1997.

10. Swiatek PJ, Lindsell CE, del Amo FF, Weinmaster G and Gridley T: Notch1 is essential for postimplantation development in mice. Genes Dev 8: 707-719, 1994.

11. Weinmaster G, Roberts VJ and Lemke G: Notch2: a second mammalian Notch gene. Development 116: 931-941, 1992.

12. Kopan R and Weintraub H: Mouse notch: expression in hair follicles correlates with cell fate determination. J Cell Biol 121: 631-641, 1993.

13. Uyttendaele H, Marazzi G, Wu G, Yan Q, Sassoon D and Kitajewski J: Notch4/int-3, a mammary proto-oncogene, is an endothelial cell-specific mammalian Notch gene. Development 122: 2251-2259, 1996.

14. Girard L, Hanna Z, Beaulieu N, Hoemann CD, Simard C, Kozak CA and Jolicoeur P: Frequent provirus insertional mutagenesis of Notch1 in thymomas of MMTVD/myc transgenic mice suggests a collaboration of c-myc and Notch1 for oncogenesis. Genes Dev 10: 1930-1944, 1996.

15. Balint K, Xiao M,Pinnix CC, Soma A, Veres I, Juhasz I, Brown EJ, Capobianco AJ, Herlyn M and Liu ZJ: Activation of Notch1 signaling is required for b-catenin-mediated human primary melanoma progression. J Clin Invest 115: 3166-3176, 2005.

16. Hoek K, Rimm DL, Williams KR, Zhao H, Ariyan S, Lin A, Kluger HM, Berger AJ, Cheng E, Trombetta ES, et al: Expression profiling reveals novel pathways in the transformation of melanocytes to melanomas. Cancer Res 64: 5270-5282, 2004.

17. Liu ZJ, Xiao M, Balint K, Smalley KS, Brafford P, Qiu R, Pinnix CC, $\mathrm{Li}$ X and Herlyn M: Notch1 signaling promotes primary melanoma progression by activating mitogen-activated protein kinase/phosphatidylinositol 3-kinase-Akt pathways and up-regulating N-cadherin expression. Cancer Res 66: 4182-4190, 2006.

18. Marino S: Medulloblastoma: developmental mechanisms out of control. Trends Mol Med 11: 17-22, 2005.

19. Hallahan AR, Pritchard JI, Hansen S, et al: The SmoA1 mouse model reveals that Notch signaling is critical for the growth and survival of sonic hedgehog-induced medulloblastomas. Cancer Res 64: 7794-7800, 2004.

20. Park JT, Li M, Nakayama K, Mao TL, Davidson B, Zhang Z, Kurman RJ, Eberhart CG, Shih IeM and Wang TL: Notch3 gene amplification in ovarian cancer. Cancer Res 66: 6312-6318, 2006.

21. Soule HD, Maloney TM, Wolman SR, Peterson WD Jr, Brenz R, McGrath CM, Russo J, Pauley RJ, Jones RF and Brooks SC: Isolation and characterization of a spontaneously immortalized human breast epithelial cell line, MCF-10. Cancer Res 50: 6075-6086, 1990.

22. Calaf GM and Hei TK: Establishment of a radiation- and estrogen-induced breast cancer model. Carcinogenesis 21: 769-776, 2000.

23. Calaf G and Hei TK: Oncoprotein expressions in human breast epithelial cells transformed by high-LET radiation. Int J Radiat Biol 77: 31-40, 2001.

24. Calaf $G$ and Russo J. Transformation of human breast epithelial cells by chemical carcinogens. Carcinogenesis 14: 483-492, 1993.

25. Califano A: SPLASH: structural pattern localization analysis by sequential histograms. Bioinformatics 16: 341-357, 2000.

26. Zajchowski DA, Bartholdi MF, Gong Y, Webster L, Liu HL, Munishkin A, Beauheim C, Harvey S, Ethier SP and Johnson PH: Identification of gene expression profiles that predict the aggressive behavior of breast cancer. Cancer Res 61: 5168-5178, 2001.

27. Sommers CL, Walker-Jones D, Heckford SE, Worland P, Valverius E, Clark R, McCormick F, Stampfer M, Abularach S and Gelmann EP: Vimentin rather than keratin expression in some hormone-independent breast cancer cell lines and in oncogene-transformed mammary epithelial cells. Cancer Res 49: 4258-4263, 1989.

28. Domagala W, Lasota J, Bartkowiak J, Weber K and Osborn M: Vimentin is preferentially expressed in human breast carcinomas with low estrogen receptor and high Ki-67 growth fraction. Am J Pathol 136: 219-227, 1990. 
29. Domagala W, Wozniak L, Lasota J, Weber K and Osborn M: Vimentin is preferentially expressed in high-grade ductal and medullary, but not in lobular breast carcinomas. Am J Pathol 137: 1059-1064, 1990.

30. Sørlie T, Perou CM, Tibshirani R, et al: Gene expression patterns of breast carcinomas distinguish tumor subclasses with clinical implications. Proc Natl Acad Sci USA 98: 10869-10874, 2001.

31. Gilles C, Polette M, Piette J, Delvigne AC, Thompson EW, Foidart JM and Birembaut P: Vimentin expression in cervical carcinomas: association with invasive and migratory potential. J Pathol 180: 175-180, 1996.

32. Heatley MK, Ewings P, Odling Smee W, Maxwell P and Toner PG: Vimentin expression does not assist in predicting survival in ductal carcinoma of the breast. Pathology 34: 230-232, 2002.

33. Kumano K, Chiba S, Kunisato A, et al: Notch1 but not Notch2 is essential for generating hematopoietic stem cells from endothelial cells. Immunity 18: 699-711, 2003.
34. Duncan AW, Rattis FM, DiMascio LN, et al: Integration of Notch and Wnt signaling in hematopoietic stem cell maintenance. Nat Immunol 6: 314-322, 2005.

35. Guentchev M and McKay RD: Notch controls proliferation and differentiation of stem cells in a dose-dependent manner. Eur J Neurosci 23: 2289-2296, 2006.

36. Stylianou S, Clarke RB and Brennan K: Aberrant activation of notch signaling in human breast cancer. Cancer Res 66: $1517-1525,2006$.

37. Frasor J, Danes JM, Komm B, Chang KC, Lyttle CR and Katzenellenbogen BS: Profiling of estrogen up- and down-regulated gene expression in human breast cancer cells: insights into gene networks and pathways underlying estrogenic control of proliferation and cell phenotype. Endocrinology 144: 4562-4574, 2003. 